\title{
Diversidade cultural e relações de gênero em uma escola indígena sul-mato-grossense ${ }^{1}$
}

\author{
Josiane Peres Gonçalves² \\ Edicleia Lima de Oliveira ${ }^{3}$
}

\section{Resumo}

As correlações entre gênero, diversidade e educação estão presentes na sociedade e na escola. Em geral, na educação infantil quase não existem docentes do gênero masculino, por se entender que essa tarefa é mais adequada às mulheres. No entanto, em algumas culturas indígenas isso é diferente, fato que despertou o interesse em entender essa realidade. Assim, este trabalho tem como objetivo investigar a opinião da comunidade escolar de uma aldeia indígena, localizada no município de Tacuru (MS), acerca do trabalho desenvolvido por professores indígenas do gênero masculino na educação infantil. A pesquisa de campo é de natureza qualitativa e para coleta de dados foi feita a gravação de entrevistas semiestruturadas, realizadas inicialmente com quatro sujeitos: um professor, um gestor escolar, uma mãe de criança, sendo todos indígenas, e uma gestora municipal não índia. Os resultados foram transcritos, analisados e nomeados como dados primários. Este estudo também contou com a participação de um pesquisador da cultura indígena que relatou sua opinião em relação aos resultados obtidos com as entrevistas dos quatro primeiros participantes. Tal participação foi denominada como dados secundários. Os dados da pesquisa evidenciam que na cultura indigena as crianças vivem junto da comunidade onde todos são educadores em potencial, independente do gênero, de modo que o cargo de professor dentro de uma aldeia indígena pode ser considerado um cargo de prestigio. Além disso, para as mulheres indígenas é mais difícil sair da aldeia em busca de uma formação, o que pode explicar a significativa presença masculina na educação infantil na aldeia indígena pesquisada.

\section{Palavras-chave}

Diversidade - Gênero - Professores Homens - Cultura indígena.

\footnotetext{
1- A pesquisa foi financiada pelo Conselho Nacional de Desenvolvimento Científico e Tecnológico - CNPq.

2- Universidade Federal de Mato Grosso do Sul Campus do Pantanal (CPAN/UFMS), Pantanal, MS, Brasil. Contato: josiane.peres@ufms.br.

3- Universidade Federal da Grande Dourados (UFGD), Grande Dourados, MS, Brasil. Contato: edicleia.oli1@gmail.com.
} 


\section{Cultural diversity and gender relations in an indigenous school in Mato Grosso do Sul (Brazil)*}

\section{Abstract}

The correlations between gender, diversity and education are present in society and in school. In childhood education, in general, there are almost no male teachers, as the task is believed to be more appropriate for women. However, this view is different in some indigenous cultures, which has aroused the interest in understanding this reality. The aim of this study was to investigate the opinion of the school community of an indigenous village, located in the town of Tacuru (MS), about the work developed by indigenous male teachers in early childhood education. The field research is qualitative in nature and the data were collected by semistructured interviews, initially conducted with four subjects: a teacher, a school manager, a child's mother (all of them indigenous), and one non-indigenous municipal manager. The results were transcribed, analyzed and named as primary data. This study also had the participation of a researcher of the indigenous culture who reported his opinion regarding the results obtained from the interviews of the first four participants. Such participation was termed secondary data. The findings show that, in the indigenous culture, children live in a community where everybody is a potential educator, regardless of gender, and the post of a teacher can be considered a prestigious position. In addition, for indigenous women, it is more difficult to leave the village in search of training, which may explain the significant male presence in early childhood education in the indigenous village at issue.

\section{Keywords}

Diversity - Gender - Male Teachers - Indigenous culture.

\section{Introdução}

Gênero, diversidade e educação são temas que se entrelaçam a todo tempo no momento atual, tornando essencial a discussão e reflexão acerca desses assuntos, para que possamos compreender de qual forma eles influenciam no ambiente escolar e na sociedade.

\footnotetext{
Ao longo do tempo temos percebido que a discussão sobre diversidade no âmbito da educação vem ganhando bastante visibilidade. Tal questão é muito importante, pois perpassa por discussões que tratam sobre o respeito às diferenças de qualquer natureza. Cabe lembrar que, uma vez que cada indivíduo se caracteriza pela sua singularidade e que a escola, por sua vez, deve levar em consideração esta dimensão da subjetividade humana em suas tomadas de decisões e encaminhamentos burocráticos, a discussão da diversidade e alteridade vai se apresentando como essencial. (TOKAIRIN; SILVA, 2012, p. 75).
} 
Ao comentar a respeito da diversidade, Oliveira (2008, p. 12230) expõe que "Em termos de definição, diversidade é propriedade da pessoa ou daquilo que é diverso; diferença; desigualdade; variedade; incoerência; oposição". Além disso, sugere que a definição do termo permite afirmar que diversidade cultural deve ser entendida, preferencialmente, como categoria individual.

Acreditamos que para além da gramática a questão da diversidade precisa ser entendida como a combinação de fatores inerentes à pessoa: origem familiar, geográfica e histórica e fatores externos, especialmente a relação com o outro. (OLIVEIRA, 2008, p. 12230).

Para Candau e Koff (2006), a diversidade refere-se à variedade de culturas e identidades culturais, em oposto à igualdade, podendo ser entendida na atualidade como um sinônimo de diálogo e de valores compartilhados. Nessa perspectiva, acredita-se que a expressão diversidade cultural, hoje, compreende a superação tanto da negação das diferenças, efetuada pela homogeneidade, como do relativismo praticado pela absolutização das diferenças. A superação dessas visões dicotômicas deve-se fazer por meio de políticas que valorizem a interação e comunicação entre os diferentes sujeitos e grupos culturais, sem homogeneizar e excluir culturas (CANDAU; KOFF, 2006).

Com relação à diversidade e educação escolar, Corrêa (2008) salienta que dentro do conceito de diversidade cultural existem as minorias, as quais por muito tempo foram caladas e omitidas do sistema escolar. Tendo como destaque as distintas classes sociais, indivíduos com necessidades educacionais diferenciadas, orientação sexual, gênero, opção religiosa, crianças, jovens, adultos, idosos, entre outros.

Entre as chamadas minorias estão presentes os grupos indígenas, no entanto, é necessário destacar que não há somente uma cultura indígena. Pode-se considerar que dentro do território brasileiro existe uma ampla e variada quantidade de culturas indígenas, as quais se caracterizam de acordo com cada povo e cada localidade, onde os grupos costumam ser ricos em detalhes, crenças, idiomas, diversidade etc.

Quando falamos em índios, precisamos estar cientes de que existe uma grande diversidade de povos, cada qual com sua cultura, seus costumes, suas crenças, modos de viver e de conceber o mundo. Essa diversidade nos impõe a necessidade de desconstruir a ideia do índio que encontra-se generalizada no imaginário da população brasileira, a fim de eliminar equívocos de que “índio é tudo igual”. (ZOIA; PERIPOLLI, 2010, p. 11).

Nesse sentido, a Secretaria de Educação Continuada, Alfabetização e Diversidade, vinculada ao Ministério da Educação e Cultura (MEC), destaca que as escolas indígenas são consideradas como lugares interculturais, debatendo e construindo conhecimentos, sendo compreendidas como escolas de fronteira, onde o ensino e a aprendizagem estão relacionados com a cultura de cada grupo indígena. Ressalta que:

[...] a educação escolar indígena problematiza enfaticamente a relação entre sociedade, cultura e escola, reassociando a escola a todas as dimensões da vida social e estabelecendo novos sentidos e 
funções a partir de interesses e necessidades particulares a cada sociedade indígena. Assim, a escola indigena será específica a cada projeto societário e diferenciada em relação a outras escolas, sejam de outras comunidades indígenas, sejam das escolas não-indígenas. (BRASIL, 2007, p. 21).

Com relação ao conceito gênero, considerado como uma forma de diversidade, Nader (2014, p. 11-12) menciona que:

\begin{abstract}
Originado do latim genus, o significado do termo gênero, dentre outros sinônimos, quer dizer o conjunto de espécies ou agrupamento de indivíduos, objetos, fatos, ideias que apresentam certo número de caracteres comuns, convencionalmente estabelecidos. [...] No campo das ciências humanas, principalmente na área de estudos sobre as mulheres, o termo gênero foi tomado de empréstimo passando a designar o caráter fundamentalmente social das distinções baseadas no sexo, implicando, portanto, na rejeição do determinismo biológico implícito nessa categoria e estabelecendo o caráter relacional das identidades feminina e masculina. Ou seja, representando o aspecto social das relações entre homens e mulheres, gênero é um conceito que se distingue do conceito biológico de sexo.
\end{abstract}

Nesse mesmo sentido, Scott (1998, p. 15) define gênero como “[...] a organização social da diferença sexual. Ele não reflete a realidade biológica primeira, mas ele constrói o sentido desta realidade". A respeito de identidade de gênero, Passos, Rocha e Barreto (2011) defendem que decorre da forma como a realidade é apresentada aos indivíduos, dos exemplos que tiveram da cultura dominante, de como são vistos e reconhecidos. Nesses aspectos, a educação recebida faz toda a diferença.

Entretanto, a identidade de gênero não se confunde com a de sexo. Enquanto essa se dá a partir do biológico, a outra (a de gênero) se forma a partir da convicção de que se tem de pertencer a um sexo, o que a caracteriza como uma construção cultural em que o biológico ganha significados sociais e esses definem e delimitam o que é ser homem e ser mulher, seus espaços e possibilidades, como se isso fosse normal e natural. (PASSOS; ROCHA; BARRET0, 2011, p. 51).

Acreditando que a identidade de gênero é desenvolvida na infância, o que se percebe é que as crianças estão indo cada vez mais cedo para as instituições escolares, no entanto, elas ficam a maior parte do tempo aos cuidados de mulheres, uma vez que praticamente não existem professores homens atuando nessa etapa da educação.

De acordo com Araujo e Hammes (2012), ainda existe uma vasta implicância no que diz respeito ao homem professor optar por trabalhar com crianças pequenas, principalmente na Educação Infantil. Isso porque, ademais de "enfrentarem o fato de que cuidar de crianças seja uma função específica da mulher, na maioria das vezes, ainda tem colocado sob suspeita a sua orientação sexual [...]”. Além disso, em alguns casos, professores homens são contristados por pais preocupados com seus filhos, por medo de que sofram algum tipo de abuso, sendo que isso dificulta cada vez mais a presença de homens professores nessa etapa da educação (ARAUJO; HAMMES, 2012, p. 8).

Ou seja, em um momento importante da vida da criança, de intenso processo de desenvolvimento, os homens não têm acompanhado e auxiliado no processo de educação das novas gerações. 
A presença masculina na educação das crianças é de aproximadamente $6 \%$ em nosso país. No entanto, esse é um dado pouco considerado nos estudos. Em nosso país, que se constituiu historicamente sob os laços de uma sociedade escravocrata e paternalista, este não é um elemento considerado importante nas análises. Assim, os pesquisadores das relações de gênero precisam considerar em suas investigações uma questão fundamental: quem são os homens que ainda atuam na educação das crianças, por que e como trabalham numa profissão reconhecida socialmente como feminina? Como, em suas trajetórias, se articulam as questões de raça/etnia, gênero e masculinidades? (EUGÊNIO, 2010, p. 2).

Se, por um lado, é nítida a ausência de professores homens trabalhando com crianças, principalmente na educação infantil, em algumas culturas indígenas essa realidade aparenta ser diferente. 0 homem participa mais intensamente do processo de educação na infância, tanto em âmbito familiar quanto nas instituições educativas.

Cabe salientar que, conforme Buss-Simão (2009), os estudos relativos à antropologia da criança têm contribuído com o:

[...] processo de apreensão dessas diferentes formas de ser criança e, inclusive, de deixar de ser criança em diferentes contextos, procurando compreender a fundo os universos autônomos e a autonomia do mundo infantil. (BUSS-SIMÃo, 2009, p. 5).

Assim, a infância não deve ser entendida como um reflexo do mundo adulto, mas, sim, como um universo diferente, com suas próprias especificidades, cabendo aos adultos a responsabilidade de garantir a educação das crianças, já desde a mais tenra idade. No caso de algumas culturas indígenas, a educação informal ocorre por meio de um processo coletivo.

[...] a aprendizagem numa comunidade indígena acontece em todos os lugares, a pedagogia é regida pelo princípio de que todos educam todos. 0 processo educativo acontece comunitariamente nas atividades que são realizadas na aldeia. É de responsabilidade da comunidade a transmissão dos saberes tradicionais do povo para as futuras gerações. Nesse processo, entende-se que a escola não é o único espaço de transmissão dos conhecimentos, de aprendizagem. A comunidade possui uma sabedoria, a qual precisa ser socializada com as crianças e os adultos são responsáveis pela formação da identidade coletiva. (ZÓIA, PERIPOLLI, 2010, p. 14).

Sendo assim, é importante entender como manifestam-se as relações de gênero, principalmente no que se refere ao trabalho de professores homens com crianças em contexto de diversidade, como é o caso de escola indígena. Dessa forma, este trabalho tem por objetivo investigar a opinião da comunidade escolar de uma aldeia indígena localizada no interior do Estado de Mato Grosso do Sul acerca do trabalho desenvolvido por professores indígenas do gênero masculino com crianças de educação infantil, destacando a opinião de um pesquisador sobre a cultura indígena em relação aos resultados obtidos. 


\section{Metodologia}

Para a produção da pesquisa foi escolhido o primórdio qualitativo, que proporciona um melhor e mais amplo entendimento sobre o assunto investigado. Suassuna (2008, p. 348) sublinha que a pesquisa qualitativa busca:

[...] não tanto em quantificar fatos e fenômenos, mas em explicar os meandros das relações sociais, considerando que a ação humana depende estreitamente dos significados que lhe são atribuídos pelos atores sociais.

As primícias para elaboração da pesquisa de campo foram efetivadas por meio de discussões realizadas no Grupo de Estudos e Pesquisa em Desenvolvimento Gênero e Educação (GEPDGE) da Universidade Federal de Mato Grosso do Sul. Em seguida, foi feita a opção por utilizar entrevistas, pois:

A entrevista como coleta de dados sobre um determinado tema científico é a técnica mais utilizada no processo de trabalho de campo. Através dela os pesquisadores buscam obter informações, ou seja, coletar dados objetivos e subjetivos. (BONI; QUARESMA, 2005, p. 72).

Com apoio desses princípios, foram elaborados roteiros semiestruturados, abrangendo os grupos de sujeitos envolvidos. A defınição do local para a realização da pesquisa foi concebida por meio de contatos telefônicos, direcionados às secretarias municipais de educação do Estado de Mato Grosso do Sul. No entanto, foi notável o reduzido número de municípios que têm professores homens atuando em turmas de educação infantil. Porém, no município de Tacuru, foi constatada a existência de uma escola indígena, onde um professor homem atuava há vários anos em uma turma, surgindo, assim, o interesse em melhor compreender essa realidade. Os resultados da pesquisa estão divididos em dados primários e secundários.

Os dados primários foram adquiridos por meio de entrevistas com quatro participantes, sendo que todos eles faziam parte da comunidade escolar da aldeia indígena investigada: 1. Guarani: professor da educação infantil, formação em magistério, atuante há 16 anos na educação; 2. Tupi: gestor escolar, formação em magistério e graduação em geografia, atuante há 20 anos na educação; 3. Cambas: gestora municipal, graduação em pedagogia, atuante há 5 anos na educação; e 4. Terena: mãe de aluno, ensino médio incompleto, agente de serviço escolar.

Os dados secundários foram obtidos por meio de gravação de entrevista com um pesquisador de cultura indigena, que emitiu opiniões sobre os dados da primeira etapa. Trata-se do professor doutor Victor Ferri Mauro, identificado no presente estudo pelo seu último sobrenome: Mauro. Ele tem graduação em ciências sociais, especialização em história e cultura dos povos indígenas, mestrado e doutorado em história.

Cabe ressaltar que o artigo contendo a base teórica, a metodologia e os resultados primários foram enviados para o professor pesquisador ter acesso antes da gravação da entrevista. Após analisar os resultados secundários, com a opinião do professor Mauro, 
foi novamente lhe enviado versão final do estudo, sendo então autorizada a divulgação do seu nome, por concordar com o que foi abordado no artigo.

\section{Resultados e discussões}

Os resultados alcançados com a pesquisa de campo encontram-se organizados em duas etapas, sendo que na primeira (dados primários) são analisadas as opiniões do professor homem, dos gestores e da mãe do aluno acerca do trabalho desenvolvido pelo professor indígena na educação infantil. Em seguida, nos dados secundários, apresentase a opinião do pesquisador especialista nas questões indígenas a respeito dos resultados apresentados nos dados primários. Nas considerações finais serão estabelecidas relações entre todas as opiniões obtidas.

\section{Dados primários}

Esses dados referem-se aos resultados da pesquisa realizada com uma parte da comunidade escolar de uma aldeia indígena, sobre o trabalho desenvolvido pelo professor homem indígena na educação infantil. Nessa etapa da pesquisa, estão inclusos um professor homem, um gestor escolar e uma mãe de criança, sendo todos indígenas. Além disso, o estudo também contou com a participação de uma gestora municipal que não é indígena.

"De qual área? Educação infantil. Primeira vez que estou vendo na minha vida professor homem trabalhando com crianças" (TUPI).

Para dar início às discussões, o relato acima refere-se a uma experiência vivenciada por Tupi. No entanto, esse fato faz parte da realidade da maioria dos professores homens que optam por trabalhar com crianças pequenas. Cada vez mais é possível encontrar pesquisas enfatizando a falta da presença masculina nessa etapa da educação básica, tendo em vista o fato de que a mulher é vista como a ideal para assumir esse papel.

Em conformidade com as palavras de Souza (2015), a docência na educação infantil, diferente das outras etapas da educação, teve seu início com a figura feminina, mantendose assim até os dias atuais. Dessa forma, historicamente quem vem se encarregando de educar e cuidar das crianças são as mulheres.

Nesse contexto, há de se considerar também que há muitas representações de gênero que foram sendo engendradas ao longo do tempo e que, embora possam ser questionadas e modificadas a partir de novos paradigmas emergentes na sociedade contemporânea, não se pode negar a força histórica que esses modos de pensar podem exercer sobre a presença masculina na Educação Infantil. (SOUZA, 2015, p. 3).

Com base na pesquisa realizada, atuante há 16 anos na área educacional, Guarani encontrava-se inserido em uma realidade distinta da apresentada anteriormente. Quando 
questionado sobre sua relação com os demais funcionários da instituição, ele ressalta não ter nenhum problema, porque na aldeia não ocorre como nas demais escolas do Estado.

É assim, eu me dou muito bem com eles, acho que é porque me conhecem, eles automaticamente me colocam na educação infantil e essa experiência eu sempre passo para eles: como eu aprendo e como as crianças aprendem. (GUARANI).

É notável, porém, que, em nossa cultura, um homem cuidar da educação de crianças parece não fazer sentido, mas em algumas culturas indigenas, ter esse profissional atuando nessa fase educacional é visto como natural e em alguns casos é até preferivel.

Bom, eu acho que até as crianças gostam do homem trabalhando. E outra coisa, até pelo convívio, eu sei também que aqui na nossa realidade, os homens dominam mais a sala de aula. As crianças..., você sabe né, na escola, quando a gente trabalha, tem que dominar a sala de aula e os homens daqui, eu vejo, tem mais poder. Na nossa cultura indígena quem domina mais é o pai e não a mãe. (TUPI).

O domínio de sala de aula por parte do professor do gênero masculino é uma continuidade do que ocorre na aldeia indígena Guarani, onde o homem detém o poder e as relações de gênero são desiguais.

A situação da mulher guarani não difere muito da situação das mulheres da nossa cultura, seu universo feminino é amplo rico e complexo, existem situações de autonomia e limites em seu cotidiano, ela está inserida em uma cultura em que o poder na grande maioria das vezes está nas mãos masculinas. (ALVES, 2011, p. 364).

Sob essa ótica, é válido salientar, de acordo com os pressupostos de Alves e Medeiros (2016), que os homens indígenas atuantes na docência em uma comunidade indígena, em sua maioria, consideram-se como guerreiros, levando em consideração o passado notável de seus povos, que lutaram destemidamente contra seus inimigos. Nessa perspectiva, a luta nos dias atuais está relacionada com a defesa do patrimônio cultural, social e histórico de seus povos. Sendo assim, somente um guerreiro bem preparado poderia lutar para preservar esses aspectos. Nesse contexto, a figura feminina não aparece, o que torna possível afırmar que há uma diferença entre os papéis desempenhados por homens e por mulheres no cenário indígena.

Esses homens professores sugerem que suas novas flechas - instrumento de caça e defesa - são os conhecimentos adquiridos em seus processos formativos, cabendo às mulheres uma participação mínima nesse processo, haja vista que, em muitas culturas, o trabalho de guerra é masculino. Entendendo que ao negarem, de certa forma, a participação das mulheres nos processos de transformações, esses professores homens indígenas talvez "cerquem" a participação feminina em alguns processos de liderança. (ALVES; MEDEIROS, 2016, p. 264).

Ao comentar acerca da aceitação da comunidade escolar a respeito do trabalho desenvolvido pelo professor indígena, Cambas menciona que, no ano anterior, o professor trabalhava apenas em um período, porém a aceitação foi tão boa que ele passou a trabalhar o dia todo: 
[...] esse ano ele trabalhou com duas turmas, uma de manhã e uma a tarde. Por causa da boa aceitação e da aprendizagem. Então, se ele está na pré-escola hoje com duas turmas, é pela aceitação. (CAMBAS).

Em oposto a essa realidade, na nossa cultura os homens professores têm de enfrentar uma série de obstáculos quando se diz respeito à atuação com crianças na educação infantil, como é relatado em uma pesquisa feita em outro município de Mato Grosso do Sul, realizada por Araujo e Hammes (2012), em que destacam que:

O sujeito "D" (2011) também afırma que a educação infantil não é lugar para homens "Não consigo ver os homens na educação infantil, dando aula em terceira ou quarta séries talvez, com crianças pequenas não. É estranho homem na educação infantil, não é lugar para vocês". O sujeito "F" (2011) embora reconheça que "não é de todo descabida a presença masculina na creche, diz que é perturbador ver um homem mantendo contato direto com as crianças". (ARAUJO; HAMMES, 2012, p. 16).

Ao ser questionado se houve algum estranhamento ou discriminação da comunidade escolar pelo fato de ser homem e trabalhar com crianças, Guarani argumenta que:

Eu acho que não. Aqui na aldeia não, mas na cidade sim. As pessoas sempre perguntam: “- Mas você trabalha com criança?”, “- Eu trabalho!”, “- Você trabalha na educação infantil?”, “- Eu trabalho!” Muitas vezes para eles, eu não sei na cidade como está sendo, na pré-escola pode ser que eles [professores] ainda levam ao banheiro e aqui a gente não faz isso, né. Criança indígena já é diferente, né, porque na verdade, geralmente, isso quem faz é só a mulher, né. Eles [indígenas] pensam assim, né, eu acredito que sim, porque isso quem faz é a mulher, né. (GUARANI).

Em conformidade com tais relatos, Prates (2008) destaca que os cuidados dispensados às crianças Guarani, inclusive em relação à saúde, é de responsabilidade feminina, que aprende a desempenhar essa função já desde a infância, visto que "[...] as meninas cuidam dos pequenos desde cedo, ajudando suas mães e parentes mulheres nas tarefas domésticas” (PRATES, 2008, p. 6).

Segundo o relato do professor indígena Guarani, as crianças indígenas só começam a frequentar a escola depois de quatro anos de idade, período em que já não precisam de muitos cuidados, os quais, na aldeia Guarani, são atribuídos somente às mulheres. Dessa forma, o professor de educação infantil pode se ocupar das atividades de ensino e, por esse motivo, possivelmente não há a rejeição por parte da comunidade escolar, por ele apenas educar, sem haver a necessidade de cuidar das necessidades básicas das crianças.

Outro fato relevante, que influencia no sentido de ter mais docentes do gênero masculino trabalhando com crianças na aldeia indígena, pode estar relacionado com a formação. Conforme destaca Tupi:

Vou falar da nossa realidade. Sou eu, o Guarani e tem mais uns cinco professores... Porque a gente, assim... a dificuldade era muito grande para a gente estudar, para fazer [ensino] superior, para ir até a rodovia, para chegar..., porque tinha uma entrada velha, longe [...]. 
Sendo assim, essas condições dificultavam o ingresso das mulheres indígenas na universidade, de modo que quem conseguia sair da aldeia e buscar formação eram os homens. Tupi argumenta que havia somente duas mulheres cursando a faculdade de Pedagogia e declara:

Então, esse é o motivo pelo qual a questão da formação de uns terem o ensino superior e aí teve essa prioridade, de quem já era formado, trabalhar com criança e por isso tem vários homens trabalhando.

Outra questão indagada aos participantes foi relativa ao reduzido número de professores do gênero masculino atuando na educação infantil. A resposta que mais ficou notória foi a discussão salarial.

Eu acredito que é questão de remuneração mesmo. Hoje, ser professor não se tem..., não dá para formar uma carreira promissora ou alguma coisa assim. A carreira do professor hoje ela é meia, é... linear, ela não oferece oportunidades, né. (CAMBAS).

Desse modo, questionamos e apresentamos a possibilidade de aumento salarial, se assim os homens demostrariam maior interesse pela profissão docente. Cambas assim mencionou:

Olha, eu não acredito também que seja só. Porque educação infantil são crianças pequenas, que exigem muita paciência, né. Tem pessoas, porque na verdade, a profissão é escolhida por perfil. E eu acredito que seriam poucos ainda, poucos homens ainda que têm essa afınidade com crianças pequenas, porque elas exigem muita paciência, muito compromisso.

Nesse mesmo sentido, Guarani declara:

Eu acredito que é porque eles não conhecem as crianças, eu acredito que eles não querem aprender com criança, eles não respeitam a criança. Não vou dizer que é porque é muito difícil dominar uma sala de aula, mas eles acreditam que é coisa de mulher.

Além de que, como discutido por Dias; Xavier (2013, p. 107):

[...] associados ao baixo status da profissão, talvez por isso, há uma preferência para que os homens atuem como coordenador, ou gestor, é como se este lugar de poder e destaque fosse natural e legítimo aos homens.

Mesmo com esses conceitos, na aldeia indígena investigada, a realidade é retratada de forma diferenciada, um aspecto considerável apresenta-se na fala de Tupi: "É por isso, eu vejo hoje na nossa realidade, a criança sempre respeita mais o homem". Nessa aldeia indígena, na casa, quem educa a criança é o pai, enquanto que a parte do cuidado, da higiene e alimentação quem realiza é a mãe. Nesse sentido, o pai é mais responsável pela educação referente a: 
Estudar, de respeitar os mais velhos, de contar histórias mais antigas, de explicar como vai ser futuramente..., isso cabe aos pais. Para quando [a criança indígena] vir para escola, ela respeitar o professor, o colega..., isso cabe mais ao pai. (TUPI).

Corroborando com essas mesmas ideias, Alves (2011, p. 364) ressalta:

O cotidiano da mulher guarani é repleto de atividades como: cuidar da família o que significa, cuidar dos filhos, preparar a comida, produzir os alimentos de subsistência na maioria das vezes em conjunto com o companheiro e afazeres domésticos. A harmonia da família e da vida em comunidade é responsabilidade de todos. 0 bem-estar do grupo não é somente individual, ele é coletivo.

Nesse contexto cultural, em que o cuidado é de responsabilidade das mulheres, enquanto que a educação para a vida é responsabilidade coletiva, ou prioritariamente função masculina (conforme relatos do Tupi), é possível afirmar que ter homens atuando como docentes de crianças acima de quatro anos, em uma aldeia Guarani, pode ser considerado como extensão do trabalho educativo existente nas famílias. Tal fato não acontece na nossa cultura, pois, historicamente, quem cuida, educa e ensina a criança é a mulher, a qual se encarrega de todas as funções referentes ao cuidado e a educação na infância, principalmente na educação infantil. Considera-se que:

[...] o cuidado e a educação das crianças pequenas têm sido difundidos como uma prerrogativa das mulheres. Isto porque convivemos ou com concepções mais ligadas ao biológico, com forte apelo à reprodução e à maternidade, ou, mesmo, em alguns casos, porque o marco teórico advém de uma perspectiva mais culturalista voltada para uma defesa política do cuidado como "trabalho feminino" - conquista histórica das mulheres. (SAYÃO, 2012, p. 152).

Consequentemente, encontramos um número crescente de mulheres atuando como docentes na educação infantil e pouquíssimos homens nesse seguimento. À vista disso, os poucos que se arriscam em atuar nesse nível escolar enfrentam dificuldades e preconceitos, pois a mulher é apontada como o ser perfeito para funções relacionadas ao cuidar e educar. "E até por que historicamente, ser professora é questão de mulher né, de mãe" (CAMBAS).

0 relato de Cambas remete a uma série de questões, como, por exemplo, o porquê de ter uma quantidade significativa de professores homens trabalhando na aldeia. Esse fato pode ser explicado pelo modo de viver dos indígenas, uma vez que a forma de sustento foi se modificando com o passar do tempo: “[...] aqui na realidade, você sabe hoje, até ano passado o pessoal ia para usina cortar cana, mas hoje, esse ano, a maioria ficou na aldeia, estão plantando" (TUPI).

Dessa forma, fazer uma graduação, no caso, uma formação docente, torna-se uma nova oportunidade de sustento, uma forma de melhorar a condição financeira e proporcionar uma realização profissional, sem ter de sair da aldeia. Januário (2002) salienta que: 
Por meio dos cursos de licenciatura indígena, os professores indios serão instrumentalizados de modo que, a partir daí, possam buscar os conhecimentos que consideram importantes na sua vida.

Nessa perspectiva, Tupi declara:

Hoje, nós aqui exemplo, nós aqui na aldeia, o professor faz pedagogia, têm aqui uns 15 professores que estão fazendo pedagogia. Então, assim eles têm interesse de trabalhar na educação porque, por exemplo, têm as leis que existem na BNDES, fala assim que, da educação infantil até o $5^{\circ}$ ano [do Ensino Fundamental] na educação indígena, quem tem que trabalhar é o indígena. Ele tem o direito de trabalhar porque fala a língua. Esses são os nossos direitos, na realidade. Então, aqui nós estamos trabalhando com 62 professores, mistos [indígena e não indígena], mas assim, eu vejo assim, eu não sei também, por isso que eu falo né, na cidade, não sei porque o professor não quer se formar em pedagogia e não se interessa em trabalhar na Educação Infantil.

Essa conjuntura, porém, não se apresenta na cultura não indígena, uma vez que raramente se encontram homens trabalhando como professores de criança, devido às representações da sociedade de que a mulher é mais adequada para essa função. Essas representações influenciam de forma direta nesse reduzido número de profissionais do gênero masculino trabalhando com crianças.

Visto que vivemos em uma sociedade patriarcal e sexista e que tal modelo cria representações consensuais sobre a naturalização da dominação masculina, podemos relacionar essa forma de hierarquização social, criada a partir dos estereótipos de gênero, com a estruturação da desigualdade e das diferentes formas de expressão da violência de gênero na sociedade. As desigualdades apresentam-se das mais diversas formas, na separação dos espaços, na destinação das profissões, nas práticas escolares, entre outros. (LANGAMER; TIMM, 2013, p. 24719).

Nesse contexto, as creches e escolas estão repletas da figura feminina e raramente se encontra a figura masculina. No entanto, como relatado no decorrer desse estudo, em uma escola indígena localizada em um município de Mato grosso de Sul, é possível encontrar uma satisfatória quantidade de professores homens trabalhando com crianças pequenas. Em uma de suas falas, Guarani afirma que deveria aumentar o número de professores homens:

Eu acredito que tem que aumentar, isso não cabe só para mulher. Por exemplo, eu gosto muito de cozinhar, mas não gosto de lavar a louça, esta responsabilidade não é só para mulher, eu acredito que os homens também têm que fazer isso, têm que gostar também da profissão [docente] principalmente na educação infantil, têm que gostar para dividir a responsabilidade. (GUARANI).

0 trabalho desses profissionais é tão bem visto por parte da comunidade indígena que as famílias preferem tê-los como docentes de suas crianças: 
Sempre falam dele, que ele é bom professor. Dizem que quando sai daqui, da mão dele, [as crianças] já sabem algumas coisas, a rumo, letra ele já sabe, escreve o nome... Se pudesse eu queria que ele [filho] fosse até final, até ele crescer sabe? (TERENA).

Nesse cenário, o professor indígena relata que os pais levam em consideração a experiência do professor, ponderando que:

As minhas crianças já sabem escrever o nome e os pais que vem aqui falam: "Ano que vem meu filho vai estudar contigo, meu filho eu quero contigo". Ou seja, ele vê a experiência de cada professor. [...] ano passado eu até estranhei, foi um "converseiro", uma mãe veio e falou comigo: "Eu quero mandar o meu filho para você cuidar!”. Veio assim e falou assim comigo e eu disse que até quero, mas não posso, porque a criança não tem 4 anos ainda, não vai ser nem matriculado ainda. Ela [mãe] disse que quer mandar para eu cuidar e eu falei: "Não, eu não posso aceitar isso, eu tenho responsabilidade com aquele que está matriculado". (GUARANI).

É notório que, na cultura indígena investigada, o trabalho do professor homem é muito bem visto e aceito por parte da comunidade. A grande preocupação é em relação à formação desses profissionais, não estabelecendo relações com o gênero do professor. Para os professores homens nessa comunidade indígena, a docência apresenta-se como uma forma de garantir o sustento e de realização profissional. Diferente de nossa cultura em que:

A docência dedicada à infância é uma área profissional que ilustra a segmentação decorrente dessa perspectiva de divisão sexual do trabalho, com o trabalho das mulheres associado à esfera reprodutiva e o dos homens, à esfera produtiva. A educação de crianças pequenas é associada ao âmbito do trabalho doméstico e à esfera reprodutiva, sendo, dessa forma, naturalizada como área de atuação feminina. (MONTEIRO; ALTMANN, 2014, p. 723).

Fica evidente que o trabalho do professor homem na educação infantil é caso de muitas opiniões, no entanto, em qualquer que seja a cultura, independente do gênero do professor, o trabalho desenvolvido por esses profissionais deve ser respeitado.

\section{Dados secundários}

Esses dados referem-se aos resultados da entrevista realizada com um pesquisador da cultura indígena, o professor doutor Victor Ferri Mauro, em que emitiu opiniões sobre os dados primários, os quais foram obtidos por meio de entrevista com o gestor escolar, o professor, a mãe de um aluno na aldeia indígena averiguada e uma gestora municipal não índia.

"O cargo de professor é considerado um emprego bastante prestigiado em uma comunidade indígena”. Ao ser questionado sobre o porquê de haver tantos homens atuando na educação infantil na aldeia, Mauro argumenta que um cargo de professor dentro da comunidade indígena pode ser considerado como uma posição de prestígio, levando em consideração que a maioria deles tem uma baixa formação profissional e um 
dos empregos mais bem remunerados que se pode almejar é o de professor. Dessa forma, sendo formados, os indigenas podem continuar vivendo em sua comunidade, junto de sua família sem precisar sair em busca de trabalho. Nesse segmento, o entrevistado enfatiza que:

[...] são poucos os que chegam a ter uma formação para exercer ocupações que são as mais valorizadas na sociedade, um engenheiro agrônomo, um engenheiro civil, médico... Eu penso que grande parte, talvez a maioria dos indígenas que chegam a fazer um curso superior, eles se formam em licenciaturas, ou também na área da saúde. Alguns conseguem investir em postos de trabalho na função de agentes de saúde ou também como auxiliar de enfermagem. Conheço pessoas que têm nível superior e são enfermeiros, mas eu penso que a mão de obra qualificada em nível superior, majoritariamente é para atuar na área de licenciatura. (MAUR0).

Ao fazer menção desses aspectos, apresenta-se um fato muito interessante, pois tanto a profissão de professor quanto as áreas da saúde e assistência social são áreas que, na nossa cultura, são consideradas femininas, por tratar do cuidar, o qual geralmente é associado como função da mulher. Porém, em algumas culturas indígenas, essa realidade é diferente.

Para Macedo Filho (2015), as questões referentes ao cuidado na nossa sociedade patriarcal encarregam às mulheres da constante manutenção da vida, sendo incumbidas de cuidar da casa, dos membros de sua família, das crianças e das atividades domésticas, além disso:

Esse cuidado também se estende ao espaço público, quando as mulheres se incubem das práticas do cuidado com os vizinhos, amigos, nas escolas e creches (como merendeiras, professoras), nos restaurantes (cozinheiras, garçonetes), nas igrejas (freiras), nos serviços de saúde (como enfermeiras, assistentes sociais etc.). (MACEDO FILHO, 2015, p. 85).

Outra suposta explicação para a forte presença masculina na educação infantil na aldeia, segundo o pesquisador, é que nessa sociedade indígena o homem tem uma participação política mais atuante. Há também a participação feminina, porém, o professor tem um considerável poder de influência política dentro da sua comunidade, sendo reputado como uma autoridade. Então, pode ser que, talvez, pelo fato de os homens terem mais espaço dentro dessa esfera, eles ocupem mais os cargos de professores, porque é um dos poucos ofícios remunerados dentro da aldeia.

"O salário de um professor, embora na nossa sociedade seja considerado baixo, mas comparado ao poder aquisitivo dentro das aldeias indígenas, é um posto bastante prestigiado" (MAUR0). Em oposição a essa ideia, na nossa cultura percebe-se que:

Os baixos salários e baixo status social ainda são impeditivos para que homens ingressem na profissão de professores de EI, isso reflete também o contexto social que o homem ainda se encontra, onde espera-se que esse ainda seja provedor da casa, o que se torna difícil com a remuneração paga a esses trabalhadores. A desvalorização da profissão docente é acentuada no 
momento em que as mulheres começam a ocupar esse espaço, como o salário delas não seria única forma de sobrevivência da família, não havia a necessidade de serem bem remuneradas. (HENTGES; JAEGER, 2013, p. 3).

Outra pergunta interpelada ao pesquisador foi a respeito da formação, pelo fato de o homem ter mais oportunidade de sair da aldeia para estudar, como suposta explicação da predominante presença masculina na educação infantil, nessa realidade.

Pode ter influência por eles terem, talvez, um acesso mais facilitado, pelas próprias relações internas da comunidade, porque eles poderiam deixar os seus filhos com as suas esposas, sendo cuidados [por elas] e teriam mais liberdade de poder ir até a cidade, talvez tendo até que dormir. Por exemplo, têm esses cursos de formação de professores, de formação continuada e ensino médio Ará Verá, que é só em Dourados. Já há mais de dez anos, os professores indígenas são levados em etapas, para se concentrarem em alojamentos na cidade, porque eles ficam 10 dias seguidos, talvez mais. Tem também o Teko Arandu, que é o curso de nível superior, a licenciatura intercultural indígena, que também trabalha em etapas concentradas. Eu vejo muitas mulheres também, atuando nisso, às vezes são professoras mulheres, casadas com professores e o casal acompanha junto essa formação. (MAURO).

Por outro lado, ele afirma que a explicação pode estar relacionada com a cultura Guarani, onde é muito comum que a mulher tenha uma vida social mais reservada dentro de casa. Elas raramente vão para a cidade e algumas têm dificuldades em falar o português. Já os homens, em geral, são mais fluentes, além de que muitos têm o costume de sair da aldeia para permanecer períodos fora:

[...] nos barracões da usina, prestando trabalhos no corte da cana, essa seria uma hipótese a ser investigada, não posso falar com certeza, mas podemos partir dessa premissa, para observar se ela se confirma. (MAUR0).

Por consequência, esse fato pode ter favorecido com que os homens fossem para a cidade, ficassem afastados da aldeia por mais tempo, estudando, fazendo uma faculdade e tendo mais aceitação da sua comunidade. No caso da mulher seria mais difícil, uma vez que:

[...] as mulheres indígenas casam-se e têm filhos mais cedo do que as mulheres não índias e esses são fatores que dificultam a presença das mulheres indígenas em uma universidade na área urbana. (MAURO).

Também Alves (2011) menciona que as mulheres Guarani casam-se precocemente, após um período de namoro com encontros discretos. 0 casamento é monogâmico e esperase que, em seguida, ela se torne mãe, porque "[...] a esterilidade feminina é percebida como castigo [...] por alguma coisa errada cometida pela mulher" (ALVES, 2011, p. 366).

0 fato de assumir compromissos com o casamento e com a maternidade precocemente justifica a dificuldade de as mulheres indígenas saírem das aldeias para cursar o ensino 
superior na cidade. Sem formação, torna-se mais difícil assumir a função de professora e este, possivelmente, seja um dos motivos pelos quais existem mais docentes do gênero masculino na aldeia indigena pesquisada.

Quando questionado a respeito das mudanças que vêm ocorrendo na cultura indígena em decorrência da modernidade, o professor argumenta que todas as culturas se transformam com o passar do tempo por influência de diversos fatores, além disso:

[...] eu vejo aquele engajamento político em torno da reivindicação territorial, isso é muito enfatizado no ensino que parte dos adultos para as crianças, dos adultos para os jovens. Eu vejo que na discussão das problemáticas internas das comunidades indígenas, nos problemas que dizem respeito a elas, na garantia dos direitos que a constituição estende aos índios, essas comunidades são muito mais politizadas do que os jovens da cidade, mesmo os mais escolarizados. Eles [indígenas] discutem muito frequentemente questões de política interna e externa. Então eu penso assim: o futuro vai revelar uma realidade muito diferente da que tem hoje, mas não necessariamente uma extinção daquele sentimento de ser diferenciado, uma lealdade para com a sua tradição, os seus ancestrais. Não vejo que vai ocorrer em curto prazo um abandono da língua, mas certamente intensificará a interação com o não índio. Pode ter certeza que cada vez mais haverá indígenas frequentando os bancos das escolas, das universidades, dos postos de trabalho na cidade [...], até porque na aldeia não tem muitas alternativas de emprego, então isso vai acontecer. (MAURO).

De forma geral, o pesquisador evidencia algumas possibilidades da presença do professor homem atuando na educação infantil na aldeia, demonstrando que os dados primários estão em conformidade com os dados secundários, ficando evidenciado que a presença desses profissionais nessa etapa da educação básica, diferente da cultura não indigena, é vista positivamente por parte da comunidade em geral.

Nesse contexto, a função docente, no âmbito da aldeia, representa um cargo de prestígio e uma possibilidade de garantir a renda e sustento da família, sem ter que sair do ambiente em que se encontram inseridos. No entanto, cabe ressaltar que não existe somente um tipo de cultura indígena, existem várias e cada uma apresenta suas especificidades. Dessa forma, esses resultados podem variar de cultura para cultura.

\section{Considerações finais}

Este estudo teve por finalidade investigar a opinião da comunidade escolar de uma aldeia indígena localizada no município de Tacuru (MS), sobre o trabalho desenvolvido por professores indígenas do gênero masculino com crianças de Educação Infantil. Por meio dos dados primários, ficou evidente que, na cultura indígena pesquisada, o trabalho desenvolvido pelos professores homens é muito bem visto e aceito por parte da comunidade e a maioria das famílias opta por ter esses profissionais cuidando de suas crianças.

A preocupação mais notável está relacionada com a formação dos profissionais, aspecto que que não depende do gênero. Além disso, para muitos indígenas, a docência apresenta-se como uma forma de garantir sustento sem ter que sair da aldeia. Outro aspecto relevante é que nessa cultura são os homens quem educam as crianças, já as 
mulheres ficam responsáveis somente pelo cuidado. Trata-se de algo que não acontece na sociedade ocidental atual, pois na cultura dominante, a mulher é quem se encarrega de cuidar e educar as crianças.

Por meio dos dados secundários, fica manifesto, de acordo com as falas do pesquisador, que ainda temos uma realidade de poucos indígenas que fazem um curso superior e, entre esses poucos casos, a maioria opta por fazer cursos de licenciatura ou formações voltadas para a área da saúde. Outra suposta explicação para o satisfatório número de professores indígenas atuando na educação infantil na comunidade estudada pode estar relacionada com o fato de que para as mulheres indígenas é mais difícil sair da aldeia em busca de uma formação, pois geralmente esses cursos são ofertados em lugares distantes da comunidade, exigindo pousos fora de casa. Além do mais, a maioria das mulheres indígenas constitui família cedo, o que dificulta a presença feminina atuando na docência da comunidade indigena investigada.

Cabe salientar que, tanto por meio dos dados primários quanto dos dados secundários, torna-se evidente que o papel de educador representado pelo homem no âmbito da comunidade indígena e a profissão docente entendida como uma posição de prestígio são fatores que permitem repensar os conceitos que estão postos acerca da docência na educação infantil. Isso porque na cultura hegemônica não se aceita que homens atuem na educação de crianças e o que para muitos parece estar fora do lugar, na cultura investigada esses profissionais têm a preferência.

Todavia, tudo pode variar de acordo com as representações sociais de cada grupo, dependendo da cultura em que os indivíduos estão inseridos. No que diz respeito aos professores homens, é preciso romper com as barreiras e considerar que, independente do gênero do professor, o importante é a realização de um bom trabalho, na busca por proporcionar aos sujeitos uma formação crítica e de qualidade.

\section{Referências}

ALVES, Luiz Alberto Sousa. Ser índia e mulher, vivendo na terra má: uma reflexão sobre a questão de gênero indígena. In: CONGRESSO DE TEOLOGIA DA PUCPR, 10., 2011, Curitiba. Anais eletrônicos... Curitiba: Champagnat, 2011. p. 363-370.

ALVES, Maria Isabel Alonso; MEDEIROS, Heitor Queiroz de. Gênero e educação em contextos indígenas na Amazônia: as relações que constituem a produção identitária das mulheres professoras Arara-Karo do Estado de Rondônia. Interações, Campo Grande, v. 17, n. 2, p. 257-266, abr./jun. 2016.

ARAUJO, Messias Pereira; HAMMES, Care Cristiane. A androfobia na educação infantil. Interfaces da Educação, Paranaíba, v. 3, n. 7, p. 5-20, 2012.

BONI, Valdete; QUARESMA, Sílvia Jurema. Aprendendo a entrevistar: como fazer entrevistas em ciências sociais. Revista Eletrônica dos Pós-Graduandos em Sociologia Política, Florianópolis, v. 2, n. 1 (3), p. 68-80, jan./jul. 2005. 
BRASIL. Secretaria de Educação Continuada, Alfabetização e Diversidade. Educação escolar indígena: diversidade sociocultural indígena ressignificando a escola. Brasília, DF: Secad, 2007. (Cadernos Secad; abril 2017).

BUSS-SIMÃO, Márcia. Antropologia da criança: uma revisão da literatura de um campo em construção. Revista Teias, Rio de Janeiro, v. 10, n. 20, p. 1-16, 2009.

CANDAU, Vera Maria; KOFF, Adélia Maria Nehme Simão. Didática e perspectiva multi/intercultural dialogando com protagonistas do campo. Educação \& Sociedade, Campinas, v. 27, n. 95, p. 471-493, maio/ago. 2006. CORRÊA, Roberto Lobato. Cultura e diversidade. Curitiba: Ibepex, 2008.

DIAS, Alfrancio Ferreira; XAVIER, Antonio Jeferson. A ausência de educadores do sexo masculino nas creches da cidade de Jequié. Saberes em Perspectiva, Jequié, v. 3, n. 5, p. 103-115, jan./set. 2013.

EUGÊNIO, Benedito Gonçalves. Narrativas de professores homens no magistério dos anos iniciais do ensino fundamental. In: FAZENDO GÊNERO, 9., 2010, Florianópolis, 2010, Anais...: diásporas, diversidades, deslocamentos. Florianópolis: UFSC, 2010. p. 1-9.

HENTGES, Karine Jacques; JAEGER, Angelita Alice. Relações de gênero, masculinidade e docência masculina. 2013. Monografia (Especialização em Movimento Humano, Sociedade e Cultura) - Centro de Educação Física e Desporto da Universidade Federal de Santa Maria. Porto Alegre: UFSM, 2013.

JANUÁRI0, Elias. Ensino superior para índios: um novo paradigma na educação. Cadernos de Educação Escolar Indígena - $3^{\circ}$ Grau Indígena, Barra do Bugres, v. 1, n. 1, p. 15-24, 2002.

LANGAMER, Stefany Ferreira; TIMM, Flávia Bascunan. Representações sociais de gênero em crianças: uma experiência no ensino fundamental. In: CONGRESSO NACIONAL DE EDUCAÇÃO (EDUCERE), 11., 2013, Curitiba. Anais... Curitiba: PUCPR, 2013. p. 24718-24734.

MACEDO FILHO, Roberto. Cuidado. In: FLEURY-TEIXEIRA, Elizabeth Maria; MENEGHEL, Stela Nazareth (Org.). Dicionário feminino da infâmia: acolhimento e diagnóstico de mulheres em situação de violência. Rio de Janeiro: Fiocruz, 2015. p. 84-86.

MONTEIRO, Mariana Kubilius; ALTMANN, Helena. Homens na educação infantil: olhares de suspeita e tentativas de segregação. Cadernos de Pesquisa, São Paulo, v. 44, n. 153, p. 720-741, 2014.

NADER, Maria Beatriz. Gênero e sexualidade. In: NADER, Maria Beatriz; RANGEL, Lívia de Azevedo Silveira (Org). Mulher e gênero em debate: representações, poder e ideologia. Vitória: Edufes, 2014. p 11-15.

OLIVEIRA, Camila Alberto Vicente de. 0 conceito de diversidade cultural e suas implicações para a formação do professor de matemática no interior de Mato Grosso: estudo de caso com licenciados em matemática na Unemat - Barra do Bugres - MT. In: CONGRESSO NACIONAL DE EDUCAÇÃO (EDUCERE), 7., 2008 e CONGRESSO IBERO-AMERICANO SOBRE VIOLÊNCIA NAS ESCOLAS (CIAVE), 3., 2008, Curitiba. Anais... Curitiba: PUCPR, 2008. p. 12228-12234.

PASSOS, Elizete; ROCHA, Nívea; BARRETO, Maribel. Gênero e educação. In: COSTA, Ana Alice Alcantara; RODRIGUES, Alexnaldo Teixeira; VANIN, Iole Macedo (Org.). Ensino e gênero: perspectivas transversais. Salvador: UFBA, 2011. p. 49-60. 
PRATES, Maria Paula. Corporalidade e gênero: reflexões possíveis sobre mulheres e crianças Mbyá-Guarani. REUNIÃO BRASILEIRA DE ANTROPOLOGIA, 26., 2008, Porto Seguro. Anais... Porto Seguro: ABA, 2008. Disponível em: <http://www.abant.org.br/conteudo/ANAIS/CD_Virtual_26_RBA/grupos_de_trabalho/ trabalhos/GT\%2014/maria\%20paula\%20prates.pdf>. Acesso em: 27 nov. 2017.

SAYÃO, Deborah Thomé. Relações de gênero e trabalho docente na educação infantil: um estudo de professores em creche. 2005. 263 f. Tese (Doutorado em Educação) - Centro de Ciências da Educação da Universidade Federal de Santa Catarina, Florianópolis, 2005.

SCOT, Joan. Gênero: uma categoria útil de análise histórica. Educação e Realidade, Porto Alegre, v. 2, n. 20, p. 71-99, jul./dez, 1998.

SOUZA, José Edilmar de. Homem docência com crianças pequenas: um olhar das crianças de um centro de educação infantil. REUNIÃO NACIONAL DA ANPED, 37., 2015, Florianópolis. Anais... Florianópolis: UFSC, 2015. p. 1-17.

SUASSUNA, Lívia. Pesquisa qualitativa em educação e linguagem: histórico e validação do paradigma indiciário. Perspectiva, Florianópolis, v. 26, n. 1, p. 341-377, jan./jun. 2008.

TOKAIRIN; Cristiane de Oliveira; SILVA; Grazielle Cristina. Diversidade e a construção social da escola. In: SEMANA DA EDUCAÇÃO DA UEL, 14., 2012, Londrina. Anais...: Pedagogia 50 anos: da Faculdade de Filosofia, Ciências e Letras da Universidade Estadual de Londrina. Londrina: UEL, 2012. p. 75-89.

ZÓIA, Alceu; PERIPOLLI, Odimar J. Infância indígena e outras infâncias. Espaço Ameríndio, Porto Alegre, v. 4, n. 2, p. 9-24, jul./dez. 2010. Disponível em: <http://www.seer.ufrgs.br/index.php/EspacoAmerindio/ article/view/12647/10473>. Acesso em: 11 nov. 2016.

Recebido em: 10.09.2017

Modificações em: 16.11.2017

Aprovado em: 18.12.2017

Josiane Peres Gonçalves é doutora em educação pela Pontifícia Universidade Católica do Rio Grande do Sul (PUCRS). Professora permanente do Programa de Pós-graduação em Educação da Universidade Federal de Mato Grosso do Sul, Campus do Pantanal (CPAN/UFMS) e do Programa de Pós-Graduação em Educação da Faculdade de Educação (FAED/UFMS). Líder do Grupo de Estudo e Pesquisa em Desenvolvimento, Gênero e Educação (GEPDGE).

Edicleia Lima de Oliveira é mestranda em educação pela Universidade Federal da Grande Dourados (UFGD); graduada em pedagogia pela Universidade Federal de Mato Grosso do Sul, Campus de Naviraí (UFMS/CPNV). Atuou como bolsista de iniciação científica - PIBIC/CNPq por dois anos durante a graduação. 